\title{
Effects of Drying Process on the Volatile and Non-Volatile Flavor Compounds of Lentinula edodes
}

\author{
Lijia Zhang ${ }^{1}$, Xiaobo Dong ${ }^{1,2}{ }^{,}$Xi Feng ${ }^{3}$, Salam A. Ibrahim ${ }^{4}$, Wen Huang ${ }^{1}$ and Ying Liu ${ }^{1, *}$ (i) \\ 1 College of Food Science and Technology, Huazhong Agricultural University, Wuhan 430070, China; \\ 13297021290@163.com (L.Z.); xbdong@nwafu.edu.cn (X.D.); huangwen@mail.hzau.edu.cn (W.H.) \\ 2 College of Food Science and Engineering, Northwest A\&F University, Xianyang 712100, China \\ 3 Department of Nutrition, Food Science and Packaging, San Jose State University, San Jose, CA 95192, USA; \\ xi.feng@sjsu.edu \\ 4 Department of Family and Consumer Sciences, North Carolina A\&T State University, 171 Carver Hall, \\ Greensboro, NC 27411, USA; ibrah001@ncat.edu \\ * Correspondence: yingliu@mail.hzau.edu.cn; Tel.: +86-13407161906
}

check for updates

Citation: Zhang, L.; Dong, X.; Feng, X.; Ibrahim, S.A.; Huang, W.; Liu, Y. Effects of Drying Process on the Volatile and Non-Volatile Flavor Compounds of Lentinula edodes. Foods 2021, 10, 2836. https://doi.org/ $10.3390 /$ foods 10112836

Academic Editors: Antonio

José Pérez-López and

Luis Noguera-Artiaga

Received: 14 October 2021

Accepted: 15 November 2021

Published: 17 November 2021

Publisher's Note: MDPI stays neutral with regard to jurisdictional claims in published maps and institutional affiliations.

Copyright: (c) 2021 by the authors. Licensee MDPI, Basel, Switzerland. This article is an open access article distributed under the terms and conditions of the Creative Commons Attribution (CC BY) license (https:/ / creativecommons.org/licenses/by/ $4.0 /$ )

\begin{abstract}
In this study, fresh Lentinula edodes was dehydrated using freeze-drying (FD), hot-air drying (HAD), and natural drying (ND), and the volatile and non-volatile flavor compounds were analyzed. The drying process changed the contents of eight-carbon compounds and resulted in a weaker "mushroom flavor" for dried L. edodes. HAD mushrooms had higher levels of cyclic sulfur compounds $(56.55 \mu \mathrm{g} / \mathrm{g})$ and showed a stronger typical shiitake mushroom aroma than those of fresh $(7.24 \mu \mathrm{g} / \mathrm{g}), \mathrm{ND}(0.04 \mu \mathrm{g} / \mathrm{g})$, and FD mushrooms $(3.90 \mu \mathrm{g} / \mathrm{g})$. The levels of $5^{\prime}$-nucleotide increased, whereas the levels of organic acids and free amino acids decreased after the drying process. The dried L. edodes treated with FD had the lowest levels of total free amino acids $(29.13 \mathrm{mg} / \mathrm{g})$. However, it had the highest levels of umami taste amino acids $(3.97 \mathrm{mg} / \mathrm{g})$, bitter taste amino acids $(6.28 \mathrm{mg} / \mathrm{g})$ and equivalent umami concentration (EUC) value (29.88 g monosodium glutamate (MSG) per $100 \mathrm{~g}$ ). The results indicated that FD was an effective drying method to produce umami flavor in dried mushrooms. Meanwhile, HAD can be used to produce a typical shiitake mushroom aroma. Our results provide a theoretical basis to manufacture L. edodes products with a desirable flavor for daily cuisine or in a processed form.
\end{abstract}

Keywords: Lentinula edodes; drying methods; volatile compounds; non-volatile compounds; sulfur compounds; free amino acids; $5^{\prime}$-nucleotide

\section{Introduction}

Lentinula edodes (Berk.) Sing or Shiitake mushroom, accounting for about $17 \%$ of global mushroom production, is the second largest cultivated edible mushroom in the world [1,2]. The global production of cultivated mushrooms has increased more than $73 \%$ in the last 10 years (FAOSTAT, 2019). L. edodes is one of the most popular edible and medicinal mushrooms in East Asia for its rich nutrients, favorable medicinal properties as well as desirable flavor $[3,4]$. Shiitake mushroom has been widely used as a flavor enhancer in meat and fermented products due to its unique flavor [5,6].

The desirable flavor of shiitake mushrooms is composed of volatile and non-volatile components [3]. It has been identified with various volatile compounds from L. edodes. The major volatile components are eight-carbon (C8) compounds and sulfur compounds [1]. Both $\mathrm{C} 8$ and sulfur compounds are produced by enzymatic reactions, in which lipoxygenase and hydroperoxide lyase catalyze linoleic acid to produce C8 compounds, such as 1octen-3-one and 1-octen-3-ol, whereas $\gamma$-glutamyl transpeptidase and cysteine sulfoxide lyase catalyze lenthinic acid to produce sulfur compounds, including 1,2,4-trithiolane and lenthionine [7,8]. Among these volatile compounds, 1-octen-3-ol, widely present in mushrooms, is responsible for a typical mushroom-like odor, whereas lenthionine, 
a cyclic 5-sulfur compound, also contributes to the aroma of L. edodes [9,10]. Fresh shiitake mushroom gives off a slight odor by the abundance of 1-octen-3-ol. However, the unique aroma of shiitake mushroom develops due to the increase of sulfur compounds after drying [1]. The taste of mushrooms is mainly triggered by several small water-soluble substances, including organic acids, $5^{\prime}$-nucleotides and free amino acids [11]. Thus, it is vital to investigate the effects of processing methods on volatile and non-volatile compounds of shiitake mushrooms.

Drying is a convenient and effective technique to prolong the shelf life of fresh shiitake mushrooms by decreasing the moisture content $[12,13]$. However, the quality of mushrooms (flavor, nutrients, texture and color) is affected by the drying method [12]. Hot-air drying (HAD), freeze-drying (FD) and natural drying (ND) are the three most typical drying methods for shiitake mushrooms. Lu et al. [14] studied the changes of volatile components in L. edodes during the vacuum freeze-drying process. Qin et al. [15] evaluated the changes in aroma profile of L. edodes during different stages of HAD. Politowicz et al. [12] investigated the effects of different drying methods (CD (convective drying), FD (freeze-drying), VMD (vacuum-microwave drying) and CPD-VMFD (vacuum-microwave finish-drying)) on volatile composition and sensory profile (inner color and sponginess) of L. edodes. However, the influence of the drying methods of hot-air drying (HAD), freeze drying (FD) and natural drying (ND) on both the volatile and non-volatile flavor compounds in L. edodes has never been studied.

The objectives of this work were to analyze the volatile and non-volatile flavor components' profile of Lentinula edodes by three drying methods (HAD, FD and ND). The results could provide theoretical evidence for new product developments with Lentinula edodes.

\section{Materials and Methods}

\subsection{Material}

Fresh shiitake mushrooms were obtained from a local market (Wuhan, China). The samples with uniform size (including the cap and stipe) and maturity were selected. The moisture contents of shiitake mushrooms were $87.50 \pm 1.30 \%$ (g/g, w.b.). Internal standard solution (cyclohexanone (99.50\% purity)) was purchased from FLUKA (Seelze, Germany). The n-alkane standards $\left(\mathrm{C}_{7}-\mathrm{C}_{30}\right)$ were purchased from Sigma Chemical Company (St. Louis, MO, USA).

\subsection{Drying Methods}

\subsubsection{Freeze-Drying (FD)}

Fresh shiitake mushrooms (1000 g) were dried by a freeze drier (Betr 2-8 LD plus, Christ, Germany). The vacuum degree was $20-40 \mathrm{~Pa}$. Cold trap temperature was $-50^{\circ} \mathrm{C}$. The drying chamber was $-35^{\circ} \mathrm{C}$. Drying was carried out for $72 \mathrm{~h}$ until the moisture content was less than $10 \%$ (g/g, w.b.) [11].

\subsubsection{Hot Air Drying (HAD)}

Fresh shiitake mushrooms (1000 g) were directly dried in a forced air circulation oven (GZX-9240MBE, Yuhua Equipment Ltd., Gongyi, China). The temperature was set at $50^{\circ} \mathrm{C}$ and the air velocity was at $0.45 \mathrm{~m} / \mathrm{s}$. Samples were dried until the final moisture content was below $10 \%$ (g/g, w.b.).

\subsubsection{Natural Drying (ND)}

Fresh shiitake mushrooms (1000 g) were placed on trays in a single layer. Samples were then placed outdoors in a well-ventilated location with abundant sunlight. The average temperature was $25 \pm 5{ }^{\circ} \mathrm{C}$ and the relative humidity was $70 \pm 10 \%$. The drying lasted for about 3 days until the final moisture content was below $10 \%$ (g/g, w.b.). 


\subsection{Electronic Nose Analysis}

An FOX 4000 electronic nose system from Alpha M.O.S. (Toulouse, France) was used for electronic nose analysis [16]. The instrument comprised of 18 metal oxide sensors and combined with a headspace auto-sampler HS100. Dried shiitake mushroom samples were ground to a fine powder and screened by a 60-meshes sifter. Then, fresh mushroom and different dried powders were homogenized in saturated sodium chloride solution (1:20), respectively. Sample of $2 \mathrm{~mL}$ were added into a $10 \mathrm{~mL}$ vial and capped with a Teflon rubber cap, equilibrated at $40{ }^{\circ} \mathrm{C}$ for $120 \mathrm{~s}$ under agitation (500 rpm). Dry air was used at a flow of $150 \mathrm{~mL} / \mathrm{min}$ as carrier gas. Equilibrated headspace $(2500 \mu \mathrm{L})$ was injected into the electronic nose at the rate of $2500 \mu \mathrm{L} / \mathrm{s}$ by a $2500 \mu \mathrm{L}$ gas-tight syringe $\left(50{ }^{\circ} \mathrm{C}\right)$. The acquisition time and delay time between consecutive injections were set as $120 \mathrm{~s}$ and $300 \mathrm{~s}$, respectively.

\subsection{HS-SPME-GC-MS Analysis}

The volatile compounds were analyzed following Jing-Nan et al.'s methods with a minor modification [17]. An SPME (solid-phase micro-extraction) manual device equipped with a $50 \mu \mathrm{m} / 30 \mu \mathrm{m}$ divinylbenzene/carboxen/polydimethylsiloxane (DVB/CAR/PDMS) fiber (Supelco, Bellfonte, PA, USA) was used to extract volatile compounds from samples. Mushroom homogenate (1.8 g mushroom powder in $20 \mathrm{~mL} \mathrm{NaCl}$ saturated solution) was added into $40 \mathrm{~mL}$-vial containing a magnetic stirring bar. After being spiked with $25 \mu \mathrm{L}$ of cyclohexanone $(0.95 \mathrm{mg} / \mathrm{mL}$ of ethyl alcohol $)$ as internal standard, the vials were immediately seal with a PTFE septa (Supelco, Bellfonte, PA, USA). Samples were balanced at $50{ }^{\circ} \mathrm{C}$ for $15 \mathrm{~min}$, then the fiber was inserted into the vial to extract volatile compounds for $1 \mathrm{~h}$. Finally, the fiber was inserted into the injection port of GC and desorbed for $5 \mathrm{~min}$ under the splitless mode.

An Agilent 7890A GC coupled with an Agilent 5975 MS was used to analyze volatile compounds. A HP-5MS fused silica capillary column $(30 \mathrm{~m} \times 0.25 \mathrm{~mm}$ I.D., $0.25 \mathrm{~mm}$ film thickness, Agilent technologies, Santa Clara, CA, USA) was installed in GC. GC conditions were set as follows: the carrier gas of helium with a flow rate of $1 \mathrm{~mL} / \mathrm{min}$; the injector temperature was $250{ }^{\circ} \mathrm{C}$; the oven temperature programming was set at $40^{\circ} \mathrm{C}$ for $3 \mathrm{~min}$ initially, then $3{ }^{\circ} \mathrm{C} / \mathrm{min}$ to $150{ }^{\circ} \mathrm{C}$, held for $1 \mathrm{~min}$, finally $5^{\circ} \mathrm{C} / \mathrm{min}$ to $220^{\circ} \mathrm{C}$, maintained for $2 \mathrm{~min}$. The ionization source temperature was set at $230^{\circ} \mathrm{C}$. The MS was obtained by electron impact mode at $70 \mathrm{eV}$ in a range from $30 \mathrm{amu}$ to $395 \mathrm{amu}$.

Volatile compounds were identified by Kovats retention index (RI) and the database (Wiley7.0 and NIST05) [15]. The Kovats retention index (RI) of unknown compounds was calculated using n-alkanes (C7-C30) injected under the same conditions. The quantity of volatiles was calculated with the internal standard (cyclohexanone) [18].

\subsection{Assay of Organic Acids}

Organic acids were extracted and analyzed as the cited method [19]. A sample (500 $\mathrm{mg}$ ) was used to extract organic acids with $25 \mathrm{~mL}$ of $\mathrm{KH}_{2} \mathrm{PO}_{4}(\mathrm{pH}=2.65)$ in $75^{\circ} \mathrm{C}$ water bath for $25 \mathrm{~min}$. The solution was centrifuged $20 \mathrm{~min}$ at $10,000 \mathrm{rpm}$, then filtered and analyzed by HPLC system. The HPLC system is equipped with an InertSustain AQ-C18 column $(4.6 \times 250 \mathrm{~mm}, 5 \mu \mathrm{m})$ (Shimadzu, Shanghai, China). Dipotassium phosphate $(0.01 \mathrm{~mol} / \mathrm{L}$, $\mathrm{pH}=2.65$ ) was used as mobile phase with a flow rate at $0.4 \mathrm{~mL} / \mathrm{min}$. The injection volume was $20 \mu \mathrm{L}$ and wavelength of the UV detector was $214 \mathrm{~nm}$. Organic acids in the samples were identified by the retention time of the standard organic acids (Sinopharm Chemical Reagent Co. Ltd., Shanghai, China) and quantified with their standard curves.

\subsection{Assay of Free Amino Acids}

According to the report [11], $1 \mathrm{~g}$ of mushroom powder and extract was obtained with $50 \mathrm{~mL}$ of hydrochloric acid $(0.10 \mathrm{~mol} / \mathrm{L})$ at $25^{\circ} \mathrm{C}$ for $45 \mathrm{~min}$. Then, centrifuged for $30 \mathrm{~min}$ at $12,000 \mathrm{rpm}$. The free amino acids were analyzed by an L-8900 high-speed amino acid analyzer (Hitachi High-Tech. Corp., Tokio, Japan). 


\subsection{Assay of $5^{\prime}$-Nucleotides}

$5^{\prime}$-nucleotides was extracted and analyzed following the cited method [11]. Sample power $(500 \mathrm{mg})$ was used to extract $5^{\prime}$-nucleotides with distilled water $(25 \mathrm{~mL})$ at $100 \pm 5^{\circ} \mathrm{C}$ for $1 \mathrm{~min}$. After centrifugation (10,000 rpm, $15 \mathrm{~min})$, the supernatant was evaporated. Then, the residue was re-dissolved in deionized water $(10 \mathrm{~mL})$. Sample of $20 \mu \mathrm{L}$ was injected to the same HPLC system as described in Section 2.5. $5^{\prime}$-nucleotide in the samples were identified by the retention time of the standard $5^{\prime}$-nucleotide (Sigma, USA) and quantified with their standard curves.

\subsection{Statistical Analysis}

Principal component analysis (PCA) was performed by XLSTAT 2010 (Microsoft Corporation, Washington, DC, USA). One way analysis of variance (ANOVA) was used to analyze the differences among samples at a significant level of 0.05 by SPSS 25 (IBM, Armonk, NY, USA).

\section{Results and Discussion}

\subsection{Electronic Nose Analysis of L. edodes Samples}

The electronic nose obtains comprehensive flavor information within a short time by mimicking the human olfactory system [20]. It was used for classifying and monitoring the drying process of L. edodes [14,21]. Principal component analysis (PCA) is a multivariate chemometric method that can be used to identify the correlation patterns of constituent variables involved in the distinction between samples [16]. PCA also can provide a better visualization and highlight the differences in volatile profiles. As shown in Figure 1, the accumulative variance contribution rate of the first two PCs was 93\% (PC1 accounted for $81.67 \%$ and PC2 accounted for $16.29 \%$ ), which indicated the feasibility of PCA and the two main components contained most of the information about volatile compounds [22]. Despite sensor instability among replications, volatile profiles from different samples were located into four separated areas. FD samples located in the positive axis of PC1, while both ND and HAD samples were in the negative axis of PC1, which indicated that the volatile compounds of ND and HAD samples were significantly different from those of FD samples. These results also showed that the drying processes altered shiitake mushroom aroma profiles.

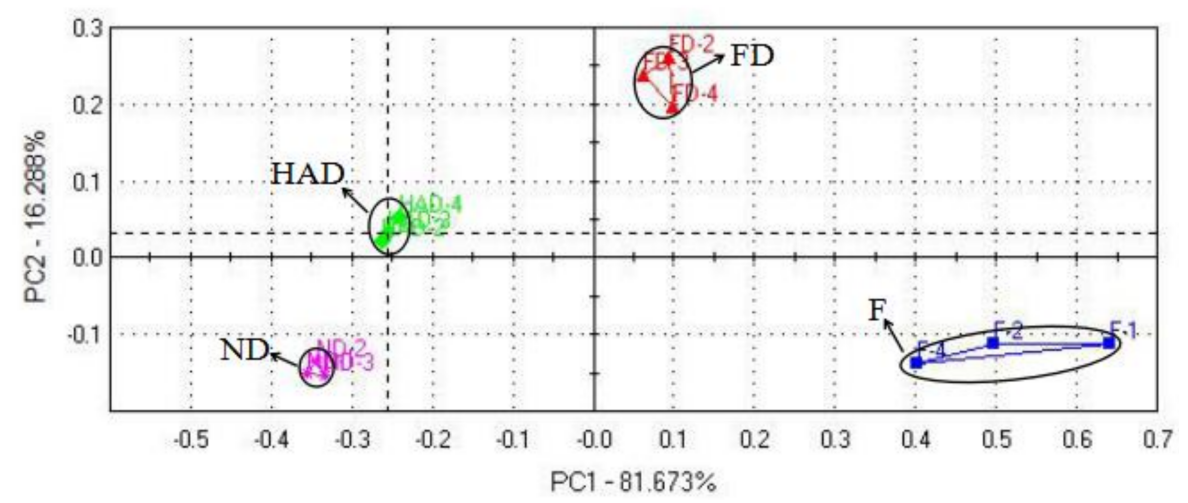

Figure 1. PCA of E-nose data for fresh and dried L. edodes; F: fresh sample; FD: freeze drying sample; HAD: hot-air drying sample; ND: natural drying sample.

\subsection{HS-SPME-GC-MS Analysis of Volatile Compounds of L. edodes}

In order to further investigate the effects of different drying methods on the flavor of L. edodes, the specific volatile components of different mushroom samples were measured by HS-SPME-GC-MS. Semi-quantitative analysis with an internal standard was used to compare differences among samples. The volatile compounds of fresh and dried mushroom samples were shown in Table 1. A total of 55 volatile compounds from L. edodes were tentatively identified and quantified, including 11 alcohols, 9 aldehydes, 6 ketones, 11 sulfur 
compounds and 17 hydrocarbons. A total of 41,36 and 24 compounds were detected in FD, HAD and ND samples, with contents of $171.29 \mu \mathrm{g} / \mathrm{g}$, $206.88 \mu \mathrm{g} / \mathrm{g}$ and $256.67 \mu \mathrm{g} / \mathrm{g}$, respectively. It is notable that only 22 compounds were detected in fresh mushroom $(1451 \mu \mathrm{g} / \mathrm{g})$. It was consistent with the reports that more volatile compounds were formed in dried L. edodes [1]. After drying treatment, the total volatile components increased, but the total volatile compounds content decreased.

Table 1. Contents of volatile compounds in fresh and different dried L. edodes.

\begin{tabular}{|c|c|c|c|c|c|c|c|}
\hline & \multirow{2}{*}{ Compounds } & \multirow{2}{*}{$\mathbf{R I}^{\mathrm{a}}$} & \multicolumn{4}{|c|}{ Contents $(\mu \mathrm{g} / \mathrm{g})$} & \multirow{2}{*}{ ID $^{\mathrm{e}}$} \\
\hline & & & $F^{b}$ & FD & HAD & ND & \\
\hline \multirow{12}{*}{ Alcohols (11) } & 1-Hexanol & 871 & $\mathrm{nd}^{\mathrm{d}}$ & 0.40 & 0.56 & 1.17 & A \\
\hline & 1-Octen-3-ol c & 983 & 857.02 & 103.78 & 5.72 & 105.30 & $\mathrm{~B}$ \\
\hline & 2-Cyclohexen-1-ol & 985 & nd & nd & 7.22 & nd & A \\
\hline & 3-Octanol ${ }^{\mathrm{c}}$ & 998 & 6.09 & 1.93 & nd & 1.40 & $\mathrm{~B}$ \\
\hline & 2-Octen-1-ol c & 1071 & 132.99 & 6.35 & 2.59 & 13.86 & $\mathrm{~B}$ \\
\hline & 1-Octanol c & 1077 & 19.89 & 1.99 & 0.68 & 2.06 & $\mathrm{~B}$ \\
\hline & Linalool & 1100 & nd & 2.13 & nd & nd & $\mathrm{A}$ \\
\hline & Phenylethyl Alcohol & 1117 & nd & 0.08 & 0.95 & nd & $\mathrm{A}$ \\
\hline & 4-Methyl-benzeneethanol & 1173 & nd & nd & 0.66 & nd & A \\
\hline & $\alpha$-Terpineol & 1188 & nd & 0.43 & nd & nd & $\mathrm{B}$ \\
\hline & Cedrol & 1596 & nd & 0.11 & nd & nd & B \\
\hline & Total alcohols & & 1015.99 & 117.20 & 18.39 & 123.79 & \\
\hline \multirow{10}{*}{ Aldehydes (9) } & Hexanal & 803 & nd & 0.34 & 4.62 & 0.02 & A \\
\hline & (E)-Hept-2-enal & 958 & nd & nd & nd & 0.18 & $\mathrm{~A}$ \\
\hline & Benzaldehyde & 965 & 0.69 & 0.62 & 1.30 & 0.15 & $\mathrm{~A}$ \\
\hline & Octanal $^{\mathrm{C}}$ & 1004 & nd & nd & 0.18 & nd & A \\
\hline & Benzeneacetaldehyde & 1046 & 0.48 & 3.44 & 0.93 & 0.32 & $\mathrm{~A}$ \\
\hline & (E)-2-Octenal ${ }^{\mathrm{C}}$ & 1058 & 11.78 & nd & 1.76 & 1.72 & $\mathrm{~A}$ \\
\hline & 2-Phenylpropenal & 1157 & nd & 0.67 & 5.64 & 0.07 & $\mathrm{~A}$ \\
\hline & Decanal & 1206 & 0.69 & 0.42 & 0.27 & 0.09 & A \\
\hline & (z)-3,7-Dimethylocta-2,6-dienal & 1241 & nd & 1.18 & nd & nd & A \\
\hline & Total aldehydes & & 13.64 & 6.67 & 14.70 & 2.55 & \\
\hline \multirow{7}{*}{ Ketones (6) } & 1-Octen-3-one ${ }^{c}$ & 981 & 237.99 & 5.52 & 21.17 & 118.24 & $\mathrm{~B}$ \\
\hline & 3-Octanone ${ }^{c}$ & 991 & 6.09 & 11.61 & 6.79 & nd & $\mathrm{B}$ \\
\hline & 3-Octen-2-one ${ }^{c}$ & 1042 & nd & nd & nd & 0.11 & A \\
\hline & Acetophenone & 1066 & nd & nd & 0.14 & 0.02 & A \\
\hline & $(+)$-Camphor & 1139 & 0.18 & 0.08 & 0.05 & 0.02 & $\mathrm{~B}$ \\
\hline & 2-Undecanone & 1297 & nd & 0.06 & 0.34 & 0.01 & A \\
\hline & Total ketones & & 244.26 & 17.27 & 28.49 & 118.40 & \\
\hline \multirow{12}{*}{$\begin{array}{c}\text { Sulfur } \\
\text { compounds } \\
\text { (11) }\end{array}$} & Carbon disulfide & $<700$ & 148.36 & 12.51 & 66.31 & 11.01 & $\mathrm{~A}$ \\
\hline & Dimethyl disulfide & 700 & nd & nd & 2.58 & nd & $\mathrm{B}$ \\
\hline & Dimethyl trisulfide & 973 & nd & 0.80 & 0.26 & nd & $\mathrm{B}$ \\
\hline & 1,2,4-Trithiolane & 1083 & 7.00 & 2.79 & 32.21 & nd & $\mathrm{B}$ \\
\hline & 2,4,5-Trithiahexane & 1121 & nd & nd & 4.87 & nd & A \\
\hline & Dimethyl tetrasulfide & 1209 & nd & nd & 2.27 & nd & A \\
\hline & 1,2,4,5-Tetrathiane & 1362 & nd & 0.11 & 7.23 & nd & $\mathrm{B}$ \\
\hline & $1,2,4,6$-Tetrathiepane & 1504 & nd & 0.01 & 3.22 & nd & $\mathrm{B}$ \\
\hline & Lenthionine & 1615 & 0.24 & 1.00 & 17.11 & 0.04 & $\mathrm{~B}$ \\
\hline & Hexathiepane & 1615 & nd & nd & 0.25 & nd & $\mathrm{B}$ \\
\hline & Cyclic octaatomic sulfur & 2000 & nd & nd & 0.29 & nd & A \\
\hline & Total sulfur compounds & & 155.60 & 17.22 & 136.60 & 11.05 & \\
\hline
\end{tabular}


Table 1. Cont.

\begin{tabular}{|c|c|c|c|c|c|c|c|}
\hline & \multirow{2}{*}{ Compounds } & \multirow{2}{*}{$\mathbf{R I}^{\mathbf{a}}$} & \multicolumn{4}{|c|}{ Contents $(\mu \mathrm{g} / \mathrm{g})$} & \multirow{2}{*}{ ID $^{\mathrm{e}}$} \\
\hline & & & $\mathbf{F}^{\mathbf{b}}$ & FD & HAD & ND & \\
\hline \multirow{17}{*}{$\begin{array}{l}\text { Hydrocarbons } \\
\text { (17) }\end{array}$} & 1,3-Xylene & 865 & nd & 0.05 & 0.04 & 0.03 & A \\
\hline & P-Isopropyltoluene & 1021 & 1.06 & 0.32 & nd & 0.03 & A \\
\hline & D-Limonene & 1025 & 17.43 & 10.54 & 7.74 & 0.78 & A \\
\hline & Naphthalene & 1176 & 0.30 & 0.33 & 0.54 & 0.02 & A \\
\hline & Dodecane & 1199 & 0.16 & 0.38 & nd & nd & A \\
\hline & 5-Ethyl-2-methyl-octane & 1280 & 0.95 & nd & nd & nd & A \\
\hline & 3-Carene & 1283 & nd & 0.07 & nd & nd & $\mathrm{B}$ \\
\hline & Decane & 1288 & nd & 0.13 & nd & nd & A \\
\hline & b-Elemen & 1390 & nd & 0.08 & nd & nd & A \\
\hline & Tetradecane & 1400 & 0.56 & 0.14 & 0.09 & 0.00 & A \\
\hline & Germacrene D & 1477 & nd & 0.08 & nd & nd & A \\
\hline & (-)-a-Selinenea- & 1491 & nd & 0.20 & nd & nd & A \\
\hline & Pentadecane & 1501 & 0.91 & 0.39 & nd & nd & A \\
\hline & Hexadecane & 1600 & nd & 0.11 & 0.05 & 0.02 & A \\
\hline & Heptadecane & 1697 & nd & 0.05 & nd & nd & A \\
\hline & Eicosane & 2000 & 0.14 & 0.06 & nd & nd & A \\
\hline & Total hydrocarbons & & 21.51 & 12.93 & 8.46 & 0.88 & \\
\hline
\end{tabular}

$\mathrm{RI}^{\mathrm{a}}$, retention index. $\mathrm{F}^{\mathrm{b}}$, fresh shiitake mushroom; FD, freeze drying sample; HAD, hot-air drying sample; ND, natural drying sample. eight-carbon ${ }^{c}$ compounds. nd $^{\mathrm{d}}$, not detected. Identification ${ }^{\mathrm{e}}$ : A, a comparison of mass spectrum and RI with authentic standards; $\mathrm{B}$, comparison of mass spectrum and RI with published data and Wiley 7.0 and NIST05 MS library.

It has been reported that alcohols, aldehydes and ketones played important roles in flavor profiles of foods $[9,10,23,24]$. As shown in Table 1, the contents of alcohols, aldehydes and ketones in fresh, FD, HAD and ND were $1273.89 \mu \mathrm{g} / \mathrm{g}, 141.14 \mu \mathrm{g} / \mathrm{g}, 61.58 \mu \mathrm{g} / \mathrm{g}$, and $244.74 \mu \mathrm{g} / \mathrm{g}$, respectively. However, the contents of alcohols and ketones significantly decreased after the drying process. Similar results were reported in other mushrooms $[9,10]$. As shown in Figure 2, alcohols were the highest in fresh samples, but decreases were shown, especially in HAD mushroom samples. The content of aldehydes in HAD mushroom samples increased slightly in comparison with fresh samples. This may be due to aldehydes mainly derived from the oxidation and degradation of unsaturated fatty acids [25]. In addition, increasing the temperature of L. edodes samples may also promote Maillard reaction, including Strecker degradation, which increased aldehyde content [26]. The content of ketones in FD samples was the lowest. It was reported that ketones are mainly obtained from the Maillard reaction and the oxidation and degradation of unsaturated fatty acids [27], and ketones can also be produced by degradation of esters [28]. However, in this study, the most probable route may be through enzymatic reactions. The preservation or formation of ketones in L. edodes was not conducive when the FD temperature was not appropriate [14].

The flavor differences between fresh and dried L. edodes were obvious. The "mushroom flavor" of fresh L. edodes is described as a sweet, earthy and cheesy aroma, while the shiitake flavor of dried L. edodes is similar to that of onion and garlic [29]. Eight-carbon compounds are ubiquitous among mushrooms, which are a key contributor to mushroom flavor [9,30]. As shown in Table 1, the contents of eight-carbon compounds in fresh, FD, HAD, and ND mushrooms were $1271.85 \mu \mathrm{g} / \mathrm{g}, 131.18 \mu \mathrm{g} / \mathrm{g}, 38.89 \mu \mathrm{g} / \mathrm{g}$ and $242.69 \mu \mathrm{g} / \mathrm{g}$, respectively. The contents of 1-octen-3-ol in in fresh, FD, HAD, and ND mushrooms were $857.02 \mu \mathrm{g} / \mathrm{g}$, $103.78 \mu \mathrm{g} / \mathrm{g}, 5.72 \mu \mathrm{g} / \mathrm{g}$ and $105.30 \mu \mathrm{g} / \mathrm{g}$, respectively. The contents of 1-octen-3-one and 3-octanone in in fresh, FD, HAD, and ND mushrooms were $244.08 \mu \mathrm{g} / \mathrm{g}, 17.13 \mu \mathrm{g} / \mathrm{g}$, $27.96 \mu \mathrm{g} / \mathrm{g}$ and $118.24 \mu \mathrm{g} / \mathrm{g}$, respectively. Generally, 1-octen-3-ol, 1-octen-3-one and 3octanone were the major C 8 compounds in mushrooms. 1-octen-3-ol, also called mushroom alcohol, feature with a typical odor of mushrooms [29]. 1-octen-3-one and 3-octanone could produce a similar odor like 1-octen-3-ol [31]. As shown in Table 1, 1-octen-3-ol and 1octen-3-one were detected in all of the four mushrooms, and fresh mushrooms had the highest level of 1-octen-3-ol and 1-octen-3-one. 3-octanone was detected in fresh, FD, and HAD mushrooms, and FD mushrooms had the highest amount. However, other research 
reported that 1-octen-3-ol and 3-octanone were the dominant compounds in the dried L. edodes (vacuum, microwave, microwave vacuum, convective drying, vacuum-microwave drying and freeze-drying) [1,12]. The differences were possibly due to the different volatile compound extraction methods. In sum, drying processes changed the contents of C8 compounds, which resulted in weaker "mushroom flavor" for dried L. edodes compared with fresh L. edodes. This interesting finding could be helpful to further understanded the biosynthesis of C8 compounds in mushrooms.

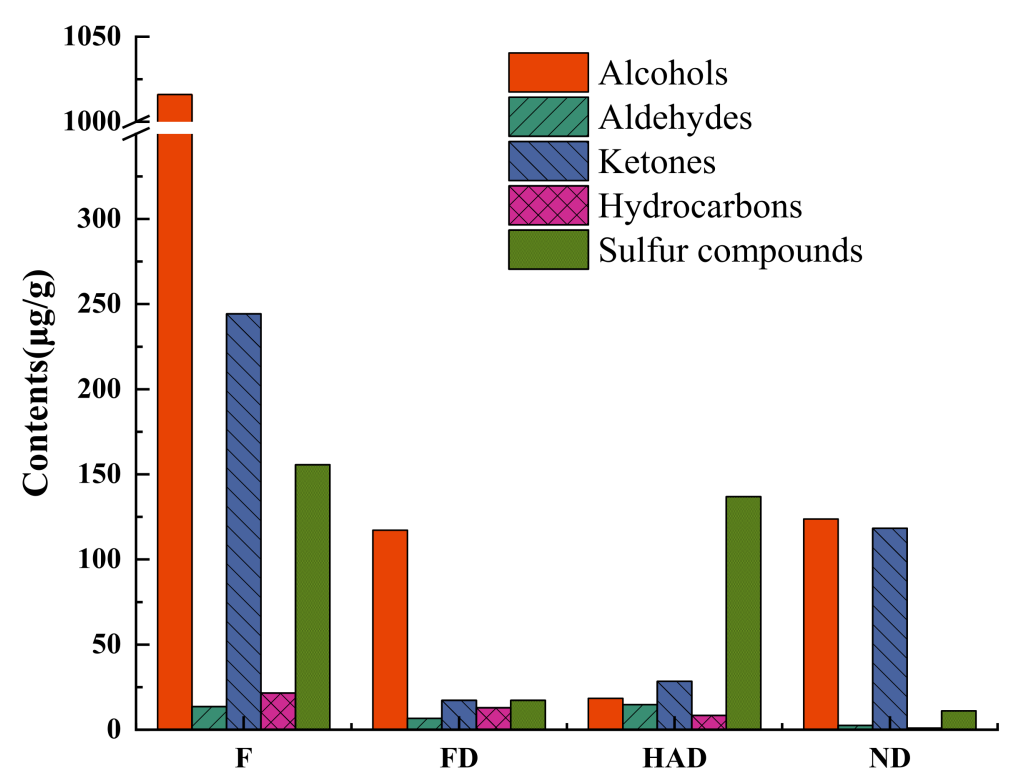

Figure 2. Contents of different types of volatile compounds in fresh and different dried L. edodes; F: fresh sample; FD: freeze drying sample; HAD: hot-air drying sample; ND: natural drying sample.

Volatile sulfur compounds are important aroma-active compounds in vegetables and processed meats, and they can offer unique aroma in L. edodes differing from many other commonly consumed mushrooms [22,32]. As shown in Table 1, the contents of sulfur compounds in mushrooms decreased after the drying process. However, more types of sulfur compounds were detected from dried mushrooms compared with fresh mushrooms. which was similar to that reported by $\mathrm{Lu}$ et al. [14]. Carbon disulfide from mushrooms had little influence in relation to the overall aroma [33]. The straight chain sulfur compounds and cyclic sulfur compounds were reported to greatly contribute to the unique aroma of L. edodes [34]. As shown in Table 1, the straight chain sulfur compounds, dimethyl disulfide and dimethyl trisulfide, were not detected in fresh and ND mushrooms, while dimethyl disulfide was detected in HAD mushrooms, and dimethyl trisulfide was detected in both FD and HAD mushrooms. The results showed that 1,2,4trithiolane, 1,2,4,5-tetrathiane and lenthionine were the main cyclic sulfur compounds detected in the four kinds of mushroom samples. HAD mushrooms had the highest level of cyclic sulfur compounds $(56.55 \mu \mathrm{g} / \mathrm{g})$ among the four mushroom samples, and the content of cyclic sulfur compounds in fresh shiitake mushroom, FD and ND were $7.24 \mu \mathrm{g} / \mathrm{g}, 3.90 \mu \mathrm{g} / \mathrm{g}$ and $0.04 \mu \mathrm{g} / \mathrm{g}$, respectively. Tian et al. [1] reported that HAD increased the content of cyclic sulfur compounds compared with fresh shiitake mushrooms. The formation of these cyclic sulfur compounds included two steps: the enzymic reactions of lenthinic acid catalyzed by cysteine sulfoxide lyase and $\gamma$-glutamyl transpeptidase; and the nonenzymatic polymerization of methylene disulfide [8]. In addition, lenthionine can decompose to dimethyl disulfide and dimethyl trisulfide [35]. Therefore, the differences of sulfur compounds in FD, HAD, and ND mushrooms might be attributed to enzyme activities and drying temperature during drying processes.

In sum, different drying processes significantly affected the volatile profiles of L. edodes, especially the C8 and sulfur compounds. HAD mushrooms had weaker "mushroom flavor" 
and strong shiitake flavor. In fact, the volatile content of L. edodes was different in each stage (fresh, early, middle and late stage) of HAD [21]. The above complicated changes of volatile compounds in mushrooms may be attributed to typical drying conditions, such as higher temperature for $\mathrm{HAD}$, long-time exposure in the sunlight for ND and vacuum evaporation for FD, which could affect volatile compounds formation and precursor degradation.

\subsection{Effects of Drying Methods on Organic Acids of L. edodes}

Organic acids (tartaric acid, malic acid, ascorbic acid, citric acid, fumaric acid and succinic acid) were detected (Table 2). As shown in Table 2, succinic acid (472.61-645.25 mg/g) was the most abundant organic acid in the samples, accounting for more than $70 \%$ of the organic acid content, followed by citric acid (107.65-142.31 mg/g) and malic acid $(21.00-36.22 \mathrm{mg} / \mathrm{g})$. Chen et al. [36] reported that the content of main organic acids was highest, in descending order, with succinic acid, citric acid and malic acid in L. edodes. These results were consistent with our results. The total content of organic acids in fresh and different dried L. edodes ranged from $621.32 \mathrm{mg} / \mathrm{g}$ to $875.82 \mathrm{mg} / \mathrm{g}$ and were in the descending order of fresh $(875.82 \mathrm{mg} / \mathrm{g}), \mathrm{ND}(695.30 \mathrm{mg} / \mathrm{g}), \mathrm{HAD}(667.82 \mathrm{mg} / \mathrm{g})$, FD $(621.32 \mathrm{mg} / \mathrm{g})$. The result was higher than that of the organic acids in other species (Agrocybe cylindracea, Pleurotus cystidiosus, Agaricus blazei, Pleurotus eryngii, Coprinus comatus), which ranged from $59.42 \mathrm{mg} / \mathrm{g}$ in to $237.81 \mathrm{mg} / \mathrm{g}$ [19]. However, compared with total organic acids of fresh L. edodes, the drying process decreased the relative contents, and FD samples were the lowest.

Table 2. Organic acid contents of fresh and different dried L. edodes.

\begin{tabular}{|c|c|c|c|c|}
\hline Organic Acids (mg/g) & $F^{a}$ & FD & HAD & ND \\
\hline Tartaric acid & $41.91 \pm 1.97^{\mathrm{A}}$ & $\mathrm{Nd}^{\mathrm{b}}$ & $12.18 \pm 0.19^{\mathrm{B}}$ & $\mathrm{Nd}^{\mathrm{b}}$ \\
\hline Malic acid & $36.22 \pm 0.70^{\mathrm{A}}$ & $27.82 \pm 0.77^{\mathrm{B}}$ & $23.57 \pm 2.35^{\mathrm{BC}}$ & $21.00 \pm 0.38^{\mathrm{C}}$ \\
\hline Ascorbic acid & $6.27 \pm 0.28^{\mathrm{A}}$ & $5.00 \pm 0.27^{C}$ & $5.66 \pm 0.11^{\mathrm{B}}$ & $4.88 \pm 0.18^{C}$ \\
\hline Citric acid & $134.49 \pm 0.45^{\mathrm{C}}$ & $107.65 \pm 2.17^{\mathrm{D}}$ & $138.13 \pm 1.90^{\mathrm{B}}$ & $142.31 \pm 1.09 \mathrm{~A}$ \\
\hline Fumaric acid & $11.68 \pm 0.03^{\mathrm{A}}$ & $8.23 \pm 0.03^{\text {В }}$ & $6.57 \pm 0.02 \mathrm{D}$ & $7.61 \pm 0.02^{C}$ \\
\hline Succinic acid & $645.25 \pm 3.03^{\mathrm{A}}$ & $472.61 \pm 3.34^{\mathrm{D}}$ & $481.71 \pm 1.72^{C}$ & $519.51 \pm 2.11^{\mathrm{B}}$ \\
\hline Total & $875.82 \pm 2.04^{\mathrm{A}}$ & $621.32 \pm 3.42^{\mathrm{D}}$ & $667.82 \pm 0.48^{\mathrm{C}}$ & $695.30 \pm 0.96^{\mathrm{B}}$ \\
\hline
\end{tabular}

Mean \pm SD $(n=3)$. Means with different superscript (A, B, C, D) in the same row are significantly different $(p<0.05)$. F a fresh shiitake mushroom; FD, freeze drying sample; HAD, hot-air drying sample; ND, natural drying sample. nd ${ }^{\mathrm{b}}$, not detected.

\subsection{Effects of Drying Methods on Free amino Acids of L. edodes}

Lentinus edodes contains a variety of amino acids. They can provide strong umami and pleasant sweet flavors [37]. As shown in Table 3, the contents of total free amino acids in fresh and dried L. edodes ranged from 29.13 to $32.82 \mathrm{mg} / \mathrm{g}$ dry weight. The total free amino acids content of the fresh samples was $32.817 \mathrm{mg} / \mathrm{g}$ dry weight, which was consistent with the reported value $(31.70 \mathrm{mg} / \mathrm{g})$ [38]. The content of total free amino acids in FD samples was the lowest. This may be due to the high temperature promoting protein hydrolysis.

Free amino acids were classified into umami, sweet, bitter and tasteless based on their taste properties [39]. As shown in Table 3, threonine was the highest sweet amino acid, accounting for $77 \%$ to $87 \%$, while glutamic acid was the highest umami taste amino acid. The results are similar to others [36]. The contents of aspartic acid were significantly increased in FD samples compared with fresh, HAD and ND. As revealed in Figure 3, fresh Lentinus edodes contained the sweetest amino acid taste, while the FD sample was the most umami-like and bitter tasting amino acid. 
Table 3. The content of free amino acids in fresh and different dried L. edodes.

\begin{tabular}{|c|c|c|c|c|c|}
\hline \multicolumn{2}{|c|}{$\begin{array}{l}\text { Free Amino } \\
\text { Acids (mg/g) }\end{array}$} & $F^{a}$ & FD & HAD & \multirow{2}{*}{$\begin{array}{c}\text { ND } \\
0.10 \pm 0.001^{\mathrm{C}}\end{array}$} \\
\hline & $A s p^{b}$ & $0.56 \pm 0.01^{\mathrm{B}}$ & $1.57 \pm 0.001^{\mathrm{A}}$ & $0.10 \pm 0.01^{C}$ & \\
\hline Umami Taste & Glu & $3.33 \pm 0.02^{\mathrm{A}}$ & $2.40 \pm 0.001^{C}$ & $3.26 \pm 0.01^{\mathrm{A}}$ & $2.76 \pm 0.003^{B}$ \\
\hline Amino Acids & total & $3.89 \pm 0.02 \mathrm{AB}$ & $3.97 \pm 0.001^{\mathrm{A}}$ & $3.36 \pm 0.02 \mathrm{AB}$ & $2.86 \pm 0.003^{\mathrm{B}}$ \\
\hline \multirow{5}{*}{$\begin{array}{l}\text { Sweet Taste } \\
\text { Amino Acids }\end{array}$} & Ala & $0.74 \pm 0.003^{\mathrm{D}}$ & $1.27 \pm 0.003^{\mathrm{B}}$ & $1.80 \pm 0.01^{\mathrm{A}}$ & $0.95 \pm 0.003^{C}$ \\
\hline & Gly & $0.77 \pm 0.003^{\mathrm{A}}$ & $0.85 \pm 0.001^{\mathrm{A}}$ & $0.80 \pm 0.01^{\mathrm{A}}$ & $0.57 \pm 0.003^{\mathrm{B}}$ \\
\hline & Ser & $0.76 \pm 0.01^{\mathrm{A}}$ & $0.72 \pm 0.003^{\mathrm{A}}$ & $0.46 \pm 0.003^{\mathrm{B}}$ & $0.39 \pm 0.003^{C}$ \\
\hline & Thr & $14.89 \pm 0.01^{\mathrm{A}}$ & $10.57 \pm 0.05^{\mathrm{B}}$ & $10.59 \pm 0.07 \mathrm{AB}$ & $13.10 \pm 0.08^{\mathrm{A}}$ \\
\hline & total & $17.16 \pm 0.02^{\mathrm{A}}$ & $13.41 \pm 0.06^{\mathrm{B}}$ & $13.65 \pm 0.08^{\mathrm{AB}}$ & $15.00 \pm 0.07^{\mathrm{A}}$ \\
\hline \multirow{8}{*}{$\begin{array}{c}\text { Bitter Taste } \\
\text { Amino Acids }\end{array}$} & Arg & $2.77 \pm 0.002^{\mathrm{A}}$ & $2.07 \pm 0.003^{C}$ & $1.51 \pm 0.01^{C}$ & $2.45 \pm 0.01^{B}$ \\
\hline & His & $0.68 \pm 0.001^{\mathrm{A}}$ & $0.55 \pm 0.001^{\mathrm{B}}$ & $0.37 \pm 0.01^{C}$ & $0.36 \pm 0.001^{C}$ \\
\hline & Ile & $0.11 \pm 0.001^{\mathrm{B}}$ & $0.43 \pm 0.001^{\mathrm{A}}$ & $0.42 \pm 0.001^{\mathrm{A}}$ & $0.15 \pm 0.001^{\mathrm{B}}$ \\
\hline & Leu & $0.20 \pm 0.001^{\mathrm{B}}$ & $0.71 \pm 0.001^{\mathrm{A}}$ & $0.66 \pm 0.01 \mathrm{AB}$ & $0.14 \pm 0.003^{\mathrm{B}}$ \\
\hline & Met & $0.10 \pm 0.001^{\mathrm{A}}$ & $0.08 \pm 0.01^{\mathrm{A}}$ & $0.07 \pm 0.003^{\mathrm{A}}$ & $0.08 \pm 0.01^{\mathrm{A}}$ \\
\hline & Phe & $0.67 \pm 0.09^{\mathrm{A}}$ & $0.79 \pm 0.01 \mathrm{~A}$ & $0.92 \pm 0.03^{\mathrm{A}}$ & $0.56 \pm 0.01^{\mathrm{B}}$ \\
\hline & Val & $1.33 \pm 0.01^{\mathrm{B}}$ & $1.64 \pm 0.003^{\mathrm{A}}$ & $1.36 \pm 0.01 \mathrm{AB}$ & $1.10 \pm 0.003^{C}$ \\
\hline & total & $5.85 \pm 0.10^{\mathrm{AB}}$ & $6.28 \pm 0.02^{\mathrm{A}}$ & $5.30 \pm 0.07^{\mathrm{AB}}$ & $4.83 \pm 0.02^{\mathrm{B}}$ \\
\hline \multirow{3}{*}{$\begin{array}{c}\text { Tasteless } \\
\text { Amino Acids }\end{array}$} & Lys & $1.16 \pm 0.003^{\mathrm{B}}$ & $1.43 \pm 0.003^{\mathrm{A}}$ & $1.17 \pm 0.001^{\mathrm{B}}$ & $0.86 \pm 0.003^{C}$ \\
\hline & Tyr & $0.28 \pm 0.01^{\mathrm{A}}$ & $0.34 \pm 0.003^{\mathrm{A}}$ & $0.42 \pm 0.03^{\mathrm{A}}$ & $0.18 \pm 0.02^{\mathrm{A}}$ \\
\hline & total & $1.44 \pm 0.02^{\text {В }}$ & $1.77 \pm 0.001^{\mathrm{A}}$ & $1.59 \pm 0.03^{\mathrm{B}}$ & $1.04 \pm 0.02^{\mathrm{B}}$ \\
\hline \multirow{2}{*}{ Others } & GABA & $0.20 \pm 0.001^{\mathrm{B}}$ & $0.13 \pm 0.003^{\mathrm{B}}$ & $0.41 \pm 0.003^{\mathrm{A}}$ & $0.51 \pm 0.001^{\mathrm{A}}$ \\
\hline & Orn & $4.29 \pm 0.01^{C}$ & $3.57 \pm 0.01^{\mathrm{D}}$ & $5.32 \pm 0.01^{\mathrm{B}}$ & $6.25 \pm 0.01^{\mathrm{A}}$ \\
\hline \multicolumn{2}{|c|}{ Total Amino Acids } & $32.81 \pm 0.09^{\mathrm{A}}$ & $29.13 \pm 0.06^{\mathrm{C}}$ & $29.61 \pm 0.08^{B C}$ & $30.48 \pm 0.03^{\mathrm{B}}$ \\
\hline
\end{tabular}

Mean $\pm \mathrm{SD}(n=3)$. Means with different superscript (A, B, C, D) within a row are significantly different $(p<0.05)$. $\mathrm{F}^{\mathrm{a}}$, fresh shiitake mushroom; FD, freeze drying sample; HAD, hot-air drying sample; ND, natural drying sample. Asp ${ }^{\mathrm{b}}$, L-Aspartic acid; Glu, L-Glutamic acid; Ala, L-Alanine; Gly, Glycine; Ser, L-Serine; Thr, L-Threonine; Arg, L-Arginine; His, L-Histidine; Ile L-Isoleucine; Leu, L-Leucine; Met, L-Methionine; Phe, L-Phenylalanine; Val, L-Valine; Lys, L-Lysine; Tyr, L-Tyrosine; GABA, $\gamma$-Aminobutyric Acid; Orn, L-Ornithine.

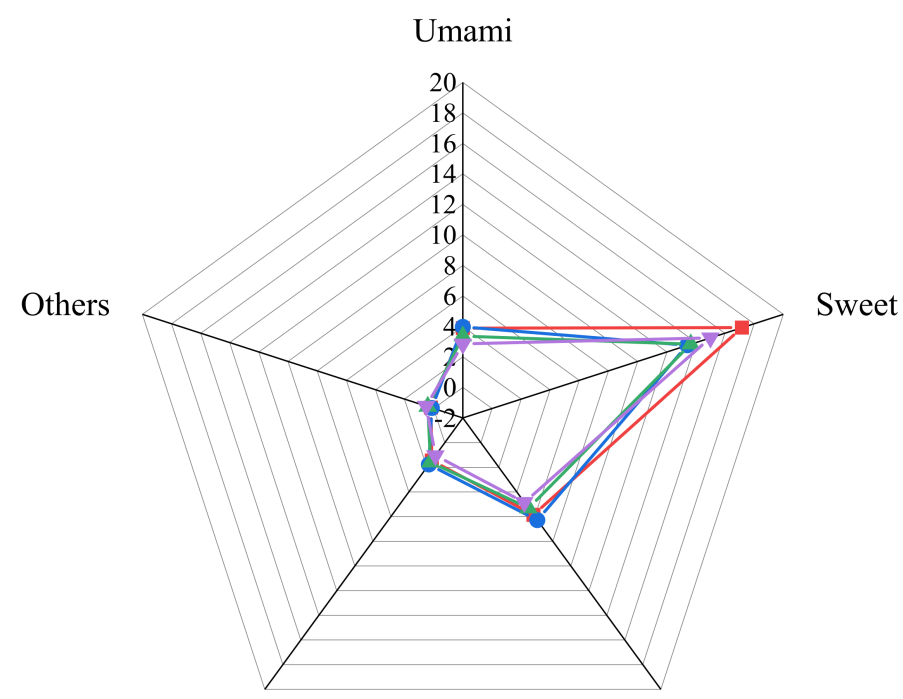

Tasteless Bitter

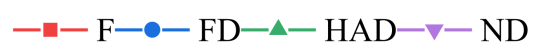

Figure 3. Radar graph of the sensory results of fresh and different dried L. edodes; F: fresh sample; FD: freeze drying sample; HAD: hot-air drying sample; ND: natural drying sample; Uma-mi = ASP + GLU; Sweet $=$ Ala + Gly + Ser + Thr; Bitter $=$ Arg + His + Ile + Leu + Met + Phe + Val; Tasteless $=$ Lys + T-yr; Other $=$ GABA + Orn .

\subsection{Effects of Drying Methods on 5'-Nucleotides of L. edodes}

$5^{\prime}$-nucleotides in mushrooms contribute to umami taste [1]. 5'-nucleotides (5'-CMP, $5^{\prime}$-UMP, $5^{\prime}$-GMP, $5^{\prime}$-AMP) were detected in this study (Table 4). As shown in Table 4, the 
total content of $5^{\prime}$-nucleotides in fresh and different dried L. edodes ranged from 7.94 to $14.41 \mathrm{mg} / \mathrm{g}$, which indicated the $5^{\prime}$-nucleotide increased after drying. In addition, $5^{\prime}$-CMP $(3.14-8.36 \mathrm{mg} / \mathrm{g})$ and $5^{\prime}$-AMP $(2.60-4.92 \mathrm{mg} / \mathrm{g})$ were found as the main $5^{\prime}$-nucleotide in L. edodes samples.

Table 4. 5'-nucleotides in fresh and different dried L. edodes.

\begin{tabular}{|c|c|c|c|c|}
\hline $5^{\prime}$-Nucleotides ${ }^{a}$ & $F^{b}$ & FD & HAD & ND \\
\hline $5^{\prime}-\mathrm{CMP}$ & $3.14 \pm 0.03^{B}$ & $2.96 \pm 0.03^{B}$ & $7.78 \pm 0.03^{\mathrm{A}}$ & $8.38 \pm 0.06^{\mathrm{A}}$ \\
\hline $5^{\prime}$-UMP & $0.27 \pm 0.02^{C}$ & $0.39 \pm 0.004^{\mathrm{B}}$ & $0.92 \pm 0.03^{B}$ & $1.92 \pm 0.09^{\mathrm{A}}$ \\
\hline $5^{\prime}-\mathrm{GMP}$ & $0.33 \pm 0.004^{\mathrm{A}}$ & $0.22 \pm 0.003^{\mathrm{A}}$ & $0.39 \pm 0.03^{\mathrm{A}}$ & $0.57 \pm 0.03^{\mathrm{A}}$ \\
\hline $5^{\prime}-\mathrm{AMP}$ & $4.25 \pm 0.01^{\mathrm{A}}$ & $4.92 \pm 0.02 \mathrm{~A}$ & $2.60 \pm 0.01^{\mathrm{B}}$ & $3.69 \pm 0.26^{\mathrm{B}}$ \\
\hline Flavor $5^{\prime}$-nucleotides ${ }^{c}$ & $0.33 \pm 0.004^{\mathrm{A}}$ & $0.22 \pm 0.003^{\mathrm{A}}$ & $0.39 \pm 0.03^{\mathrm{A}}$ & $0.57 \pm 0.03^{\mathrm{A}}$ \\
\hline MSG-like $5^{\prime}$-nucleotide ${ }^{\mathrm{d}}$ & $4.58 \pm 0.002^{\mathrm{A}}$ & $5.14 \pm 0.02^{\mathrm{A}}$ & $2.99 \pm 0.02^{\mathrm{B}}$ & $4.26 \pm 0.29^{\mathrm{A}}$ \\
\hline Total & $7.94 \pm 0.05^{\mathrm{B}}$ & $8.48 \pm 0.00^{\mathrm{B}}$ & $11.61 \pm 0.08^{\mathrm{A}}$ & $14.41 \pm 0.14^{\mathrm{A}}$ \\
\hline
\end{tabular}

Mean \pm SD $(n=3)$. Means with different superscript (A, B, C) within a row are significantly different $(p<0.05) .5^{\prime}$-CMP a, 5 -cytosine monophosphate; 5'-UMP, 5-uridine monophosphate; 5'-GMP, 5-guanosine monophosphate; $5^{\prime}$-AMP, 5-adenosine monophosphate. F b , fresh shiitake mushroom; FD, freeze drying sample; HAD, hot-air drying sample; ND, natural drying sample. Flavor $5^{\prime}$-nucleotides c: $5^{\prime}$-GMP + 5'-IMP + 5'-XMP, while only 5'-GMP was detected in this study. MSG-like $5^{\prime}$-nucleotide d: 5'-AMP $+5^{\prime}-\mathrm{GMP}+5^{\prime}$-IMP + $5^{\prime}$-XMP, while $5^{\prime}$-IMP and $5^{\prime}$-XMP was not detected in this study.

\subsection{Equivalent Umami Analysis}

The equivalent umami concentration (EUC) represents the MSG concentration, based on the synergistic effect of MSG-like components (Asp and Glu) and $5^{\prime}$-nucleotide (5'-AMP, $5^{\prime}$-GMP and $5^{\prime}$-IMP), which may enhance the umami taste of mushrooms [3]. As shown in Figure 4, the EUC value of fresh and different dried L. edodes ranged from 5.84 to $29.88 \mathrm{~g}$ MSG/100 g, which were similar to the reported results [19]. It is reported that the EUC values defined at four levels: $<10 \%$ ( $<10 \mathrm{~g}$ MSG $/ 100 \mathrm{~g}$ dry matter), $10-100 \%(10-100 \mathrm{~g}$ MSG/100 g), 100-1000\% (100-1000 g MSG/100 g) and >1000\% (>1000 g MSG/100 g) [40]. The EUC values of the HAD and ND samples at the first level ( $<10 \mathrm{~g} \mathrm{MSG} / 100 \mathrm{~g})$, fresh and FD samples at the second level (10-100 g MSG/100 g) (Figure 4). Among the four samples, the FD dried L. edodes had the highest EUC value (29.88 g MSG/100 g) and were in the descending order of FD > fresh (15.12 g MSG/100 g) > ND (7.46 g MSG/100 g) > HAD (5.84 g MSG/100 g), which proved FD as an effective drying method to produce umami tasting dried L. edodes.

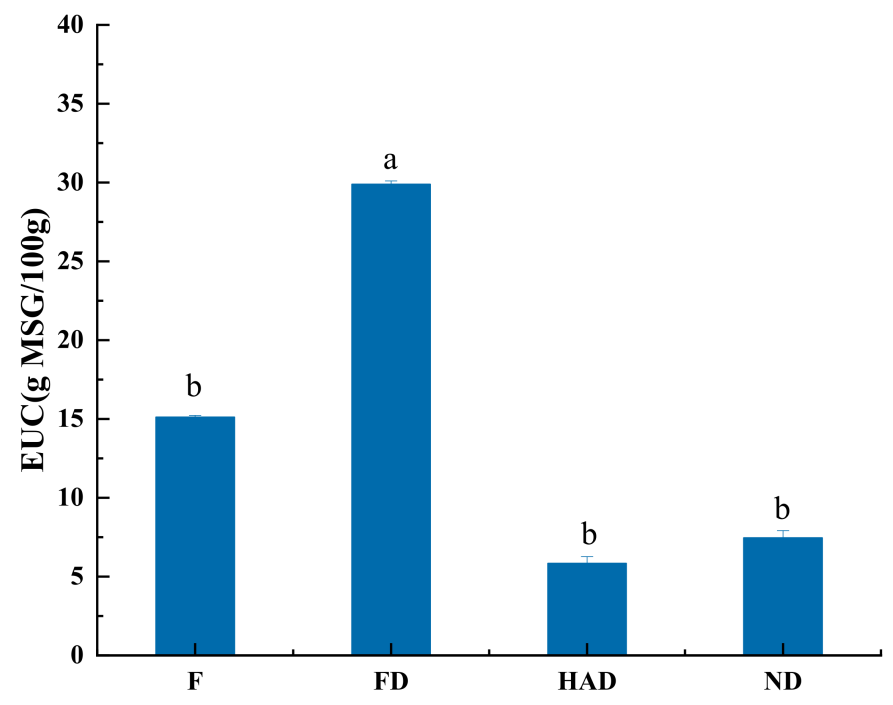

Figure 4. Equivalent umami concentration (EUC) values of fresh and different dried L. edodes; F: fresh sample; FD: freeze drying sample; HAD: hot-air drying sample; ND: natural drying sample. Means with different letters $(a, b)$ are significantly different $(p<0.05)$. 


\section{Conclusions}

In the present study, volatile and non-volatile compound profiles of L. edodes were modified by three typical drying methods (FD, HAD and ND). After drying, the content of C8 volatile compounds decreased, but sulfur compounds (straight chain and cyclic sulfurs) were increased, especially in the HAD mushrooms, which resulted in strong shiitake flavor. The drying process increased the relative contents of total $5^{\prime}$-nucleotide of L. edodes as well as the freeze-drying L. edodes had the highest levels of umami taste amino acids, bitter taste amino acids and EUC value. Hot-air drying would be a better method to produce typical shiitake mushroom aroma, while FD was an effective drying method to produce umami tasting dried L. edodes.

The growth of the global dried mushroom market is driven by the demands of organic and healthy food with a clean label. In order to provide nutrient and high-quality final products to consumers, fundamental research should be conducted to better understand the mechanisms of macro and micro-nutrient changes and flavor formation during processing. This research provided up-to-date information about the formation of volatile and non-volatile compounds during different drying processing, which could provide useful information to the mushroom industry to select the optimum method to process dried mushrooms without any preservatives and additives. Future research will focus on understanding the contribution of volatile and non-volatile compounds to sensory perception.

Author Contributions: Conceptualization, Y.L. and W.H.; methodology, L.Z. and X.D.; software, L.Z.; validation, L.Z. and W.H.; formal analysis, L.Z.; investigation, L.Z. and X.D.; resources, W.H.; data curation, L.Z.; writing — original draft preparation, L.Z. and X.D.; writing—review and editing, X.F. and S.A.I.; visualization, L.Z.; supervision, L.Z.; project administration, W.H.; funding acquisition, Y.L. All authors have read and agreed to the published version of the manuscript.

Funding: This research was funded by the Natural Science Foundation of China (No. 31601434), the Agricultural Science and Technology Innovation Center of Hubei Province (2016-620-000-001-044), Hubei Agriculture Research System (HBHZDZB-2021-023).

Institutional Review Board Statement: Not applicable.

Informed Consent Statement: Not applicable.

Data Availability Statement: Not applicable.

Conflicts of Interest: The authors declare no conflict of interest.

\section{References}

1. Tian, Y.; Zhao, Y.; Huang, J.; Zeng, H.; Zheng, B. Effects of different drying methods on the product quality and volatile compounds of whole shiitake mushrooms. Food Chem. 2016, 197, 714-722. [CrossRef]

2. Mleczek, M.; Budka, A.; Siwulski, M.; Mleczek, P.; Gasecka, M.; Jasinska, A.; Kalac, P.; Sobieralski, K.; Niedzielski, P.; Proch, J.; et al. Investigation of differentiation of metal contents of Agaricus bisporus, Lentinula edodes and Pleurotus ostreatus sold commercially in Poland between 2009 and 2017. J. Food Compos. Anal. 2020, 90, 103488. [CrossRef]

3. Gao, S.S.; Huang, Z.C.; Feng, X.; Bian, Y.B.; Huang, W.; Liu, Y. Bioconversion of rice straw agro-residues by Lentinula edodes and evaluation of non-volatile taste compounds in mushrooms. Sci. Rep. 2020, 10, 1814. [CrossRef]

4. Reis, G.C.L.; Custodio, F.B.; Botelho, B.G.; Guidi, L.R.; Gloria, M.B.A. Investigation of biologically active amines in some selected edible mushrooms. J. Food Compos. Anal. 2020, 86, 103375. [CrossRef]

5. Pil-Nam, S.; Park, K.-M.; Kang, G.-H.; Cho, S.-H.; Park, B.-Y.; Van-Ba, H. The impact of addition of shiitake on quality characteristics of frankfurter during refrigerated storage. LWT-Food Sci. Technol. 2015, 62, 62-68. [CrossRef]

6. Zhang, Y.Y.; Hartung, N.M.; Fraatz, M.A.; Zorn, H. Quantification of key odor-active compounds of a novel nonalcoholic beverage produced by fermentation of wort by shiitake (Lentinula edodes) and aroma genesis studies. Food Res. Int. 2015, 70, 23-30. [CrossRef]

7. Holighaus, G.; Weissbecker, B.; von Fragstein, M.; Schutz, S. Ubiquitous eight-carbon volatiles of fungi are infochemicals for a specialist fungivore. Chemoecology 2014, 24, 57-66. [CrossRef]

8. Liu, Y.; Lei, X.Y.; Chen, L.F.; Bian, Y.B.; Yang, H.; Ibrahim, S.A.; Huang, W. A novel cysteine desulfurase influencing organosulfur compounds in Lentinula edodes. Sci. Rep. 2015, 5, 10047. [CrossRef] 
9. Pei, F.; Yang, W.; Ma, N.; Fang, Y.; Zhao, L.; An, X.; Xin, Z.; Hu, Q. Effect of the two drying approaches on the volatile profiles of button mushroom (Agaricus bisporus) by headspace GC-MS and electronic nose. LWT-Food Sci. Technol. 2016, 72, 343-350. [CrossRef]

10. Yang, W.; Yu, J.; Pei, F.; Mariga, A.M.; Ma, N.; Fang, Y.; Hu, Q. Effect of hot air drying on volatile compounds of Flammulina velutipes detected by HS-SPME-GC-MS and electronic nose. Food Chem. 2016, 196, 860-866. [CrossRef] [PubMed]

11. Hu, S.; Feng, X.; Huang, W.; Ibrahim, S.A.; Liu, Y. Effects of drying methods on non-volatile taste components of Stropharia rugoso-annulata mushrooms. LWT-Food Sci. Technol. 2020, 127, 109428. [CrossRef]

12. Politowicz, J.; Lech, K.; Lipan, L.; Figiel, A.; Carbonell-Barrachina, A.A. Volatile composition and sensory profile of shiitake mushrooms as affected by drying method. J. Sci. Food Agric. 2018, 98, 1511-1521. [CrossRef]

13. Cheng, S.S.; Li, R.; Yang, H.M.; Wang, S.Q.; Lin, R.; Tan, M.Q. Characterisation of moisture migration of shiitake mushroom (Lentinula edodes) during storage and its relationship to quality deterioration. Int. J. Food Sci. Technol. 2020, 55, 2132-2140. [CrossRef]

14. Lu, X.; Hou, H.; Fang, D.; Hu, Q.; Chen, J.; Zhao, L. Identification and characterization of volatile compounds in Lentinula edodes during vacuum freeze-drying. J. Food Biochem. 2021, e13814. [CrossRef] [PubMed]

15. Qin, L.; Gao, J.-X.; Xue, J.; Chen, D.; Lin, S.-Y.; Dong, X.-P.; Zhu, B.-W. Changes in Aroma Profile of Shiitake Mushroom (Lentinus edodes) during Different Stages of Hot Air Drying. Foods 2020, 9, 444. [CrossRef]

16. Yao, Y.; Pan, S.; Fan, G.; Dong, L.; Ren, J.; Zhu, Y. Evaluation of volatile profile of Sichuan dongcai, a traditional salted vegetable, by SPME-GC-MS and E-nose. LWT-Food Sci. Technol. 2015, 64, 528-535. [CrossRef]

17. Ren, J.N.; Tai, Y.N.; Dong, M.; Shao, J.H.; Yang, S.Z.; Pan, S.Y.; Fan, G. Characterisation of free and bound volatile compounds from six different varieties of citrus fruits. Food Chem. 2015, 185, 25-32. [CrossRef]

18. Paraskevopoulou, A.; Chrysanthou, A.; Koutidou, M. Characterisation of volatile compounds of lupin protein isolate-enriched wheat flour bread. Food Res. Int. 2012, 48, 568-577. [CrossRef]

19. Li, X.; Feng, T.; Zhou, F.; Zhou, S.; Liu, Y.; Li, W.; Ye, R.; Yang, Y. Effects of drying methods on the tasty compounds of Pleurotus eryngii. Food Chem. 2015, 166, 358-364. [CrossRef]

20. Hotel, O.; Poli, J.P.; Mer-Calfati, C.; Scorsone, E.; Saada, S. A review of algorithms for SAW sensors e-nose based volatile compound identification. Sens. Actuators B-Chem. 2018, 255, 2472-2482. [CrossRef]

21. Zhang, H.; Peng, J.; Zhang, Y.R.; Liu, Q.; Pan, L.Q.; Tu, K. Discrimination of volatiles of shiitakes (Lentinula edodes) produced during drying process by electronic nose. Int. J. Food Eng. 2020, 16, 20190233. [CrossRef]

22. Liu, M.; Wang, J.; Li, D.; Wang, M. Electronic Tongue Coupled with Physicochemical Analysis for the Recognition of Orange Beverages. J. Food Qual. 2012, 35, 429-441. [CrossRef]

23. Choi, S.M.; Lee, D.-J.; Kim, J.-Y.; Lim, S.-T. Volatile composition and sensory characteristics of onion powders prepared by convective drying. Food Chem. 2017, 231, 386-392. [CrossRef] [PubMed]

24. Rajkumar, G.; Shanmugam, S.; Galvao, M.d.S.; Dutra Sandes, R.D.; Santos Leite Neta, M.T.; Narain, N.; Mujumdar, A.S Comparative evaluation of physical properties and volatiles profile of cabbages subjected to hot air and freeze drying. LWT-Food Sci. Technol. 2017, 80, 501-509. [CrossRef]

25. Tan, H.R.; Lau, H.; Liu, S.Q.; Tan, L.P.; Sakumoto, S.; Lassabliere, B.; Leong, K.-C.; Sun, J.; Yu, B. Characterisation of key odourants in Japanese green tea using gas chromatography-olfactometry and gas chromatography-mass spectrometry. LWT-Food Sci. Technol. 2019, 108, 221-232. [CrossRef]

26. Shi, Y.; Li, X.; Huang, A. A metabolomics-based approach investigates volatile flavor formation and characteristic compounds of the Dahe black pig dry-cured ham. Meat Sci. 2019, 158, 107904. [CrossRef] [PubMed]

27. Giri, A.; Osako, K.; Ohshima, T. Identification and characterisation of headspace volatiles of fish miso, a Japanese fish meat based fermented paste, with special emphasis on effect of fish species and meat washing. Food Chem. 2010, 120, 621-631. [CrossRef]

28. Cao, J.; Zou, X.-G.; Deng, L.; Fan, Y.-W.; Li, H.; Li, J.; Deng, Z.-Y. Analysis of nonpolar lipophilic aldehydes/ketones in oxidized edible oils using HPLC-QqQ-MS for the evaluation of their parent fatty acids. Food Res. Int. 2014, 64, 901-907. [CrossRef] [PubMed]

29. Cheng, Y.; Sun, J.; Ye, X.; Lv, B.; Chu, Y.; Chen, J. Advances on flavor substances of edible mushrooms. Sci. Technol. Food Ind. 2012, 33, 412-414.

30. Jung, M.Y.; Lee, D.E.; Baek, S.H.; Lim, S.M.; Chung, I.-M.; Han, J.-G.; Kim, S.-H. An unattended HS-SPME-GC-MS/MS combined with a novel sample preparation strategy for the reliable quantitation of C8 volatiles in mushrooms: A sample preparation strategy to fully control the volatile emission. Food Chem. 2021, 347, 128998. [CrossRef]

31. Combet, E.; Henderson, J.; Eastwood, D.C.; Burton, K.S. Eight-carbon volatiles in mushrooms and fungi: Properties, analysis, and biosynthesis. Mycoscience 2006, 47, 317-326. [CrossRef]

32. Corral, S.; Leitner, E.; Siegmund, B.; Flores, M. Determination of sulfur and nitrogen compounds during the processing of dry fermented sausages and their relation to amino acid generation. Food Chem. 2016, 190, 657-664. [CrossRef] [PubMed]

33. Ito, Y.; Toyoda, M.; Suzuki, H.; Iwaida, M. Gas-liquid-chromatographic determination of lenthionine in shiitake mushroom (lentinus-edodes) with special reference to relation between carbon-disulfide and lenthionine. J. Food Sci. 1978, 43, 1287-1289. [CrossRef]

34. Hiraide, M.; Miyazaki, Y.; Shibata, Y. The smell and odorous components of dried shiitake mushroom, Lentinula edodes I: Relationship between sensory evaluations and amounts of odorous components. J. Wood Sci. 2004, 50, 358-364. [CrossRef] 
35. Chen, C.C.; Wu, C.M. Studies on the enzymic reduction of 1-octen-3-one in mushroom (agaricus-bisporus). J. Agric. Food Chem. 1984, 32, 1342-1344. [CrossRef]

36. Chen, W.; Li, W.; Yang, Y.; Yu, H.; Zhou, S.; Feng, J.; Li, X.; Liu, Y. Analysis and Evaluation of Tasty Components in the Pileus and Stipe of Lentinula edodes at Different Growth Stages. J. Agric. Food Chem. 2015, 63, 795-801. [CrossRef] [PubMed]

37. Pei, F.; Yang, W.-J.; Shi, Y.; Sun, Y.; Mariga, A.M.; Zhao, L.-Y.; Fang, Y.; Ma, N.; An, X.-X.; Hu, Q.-H. Comparison of Freeze-Drying with Three Different Combinations of Drying Methods and Their Influence on Colour, Texture, Microstructure and Nutrient Retention of Button Mushroom (Agaricus bisporus) Slices. Food Bioprocess Technol. 2014, 7, 702-710. [CrossRef]

38. Xu, L.; Fang, X.; Wu, W.; Chen, H.; Mu, H.; Gao, H. Effects of high-temperature pre-drying on the quality of air-dried shiitake mushrooms (Lentinula edodes). Food Chem. 2019, 285, 406-413. [CrossRef]

39. Yin, C.; Fan, X.; Fan, Z.; Shi, D.; Yao, F.; Gao, H. Comparison of non-volatile and volatile flavor compounds in six Pleurotus mushrooms. J. Sci. Food Agric. 2019, 99, 1691-1699. [CrossRef] [PubMed]

40. Yang, J.H.; Lin, H.C.; Mau, J.L. Non-volatile taste components of several commercial mushrooms. Food Chem. 2001, 72, 465-471. [CrossRef] 